\title{
Psychiatric symptomatology in early-onset Binswanger's disease: two case reports
}

\author{
R.M. Lawrence ${ }^{1}$ and J.C. Hillam ${ }^{2}$ \\ 1 Department of Psychogeriatric Medicine and Neuropsychiatry, Purley Hospital, 50 Pampisford \\ Rd, Purley, Surrey CR8 2NE, and ${ }^{2}$ Department of Psychiatry, Whittington Hospital, Highgate \\ Hill, London N19 5NF, UK
}

Correspondence to: R.M. Lawrence at above address

\begin{abstract}
We describe two cases of Binswanger's disease of pre-senile onset which presented with affective and psychotic symptoms well before the appearance of cognitive deterioration and neurological signs, initially evading an accurate diagnosis. Psychiatrists should be aware of white matter disease and its role in the pathogenesis of psychiatric illness. Particular attention should be given to a history of hypertension as a risk factor in the early identification of these cases.
\end{abstract}

Keywords: Binswanger's disease - Psychopathology - Hypertension

\section{INTRODUCTION}

Binswanger's disease (BD) is characterized by white matter demyelination with luminar narrowing of penetrating medullary arteries and arterioles, causing ultimately a subcortical-cortical disconnection dementia. Periventricular white matter disease, radiologically identifiable as leukoaraiosis (Hachinski et al., 1987), is positively linked with both advancing age and hypertension, which are major risk factors towards the development of vascular dementias (Shimada et al., 1990; Yao et al., 1992). The prevalence of $\mathrm{BD}$ is as high as $5 \%$ in the over 65 year old population (Goto et al., 1981; Peterson and Summergrad 1989). Babikian and Ropper (1987) reviewed the clinical histories of 46 autopsy-confirmed cases of BD. They found an average age at onset of 57 years, with demise about 5 years later. An acute neurological event marked the onset of the disease in one-third of the cases. In the remaining two-thirds, initial changes were more insiduous. Behavioural changes and amnestic problems were early findings in $65 \%$ of cases. Psychiatrists are said to recognize BD infrequently (O'Brien, 1988; Summergrad and Peterson, 1989), but BD has been associated with a series of psychiatric features, including irritability, aggressiveness, depression, hypomania and paranoia. Such psychopathology may represent early symptoms of BD in the absence of neurological disturbance. An early diagnosis can be confirmed by radiological tech-

(C) 1995 Rapid Communications of Oxford Ltd niques, such as computed tomography (CT) or magnetic resonance imaging (MRI) scan (Van Swieten $e t$ al., 1991).

\section{CASE REPORTS}

\section{Case 1}

Mrs ST was a 58 year old right-handed hypertensive woman with a positive family history of depression in her two sisters. She first presented to the psychiatric services in 1990 at the age of 56 with an 8 month history of low mood, anhedonia and hypochondriacal delusions. She believed that she was unable to breathe because of a blocked nose and that she would die of suffocation. She also reported an increased sensitivity and intolerance of various odours coming from perfumes, food and even her hi-fi system. Her appetite was poor and she had lost more than one stone in weight during the last 12 months. She displayed diurnal mood variation with uplifting in the evening and suffered from early morning waking.

Physical examination was unremarkable except for mildly raised blood pressure $(140 / 100 \mathrm{mmHg})$. The haematological and biochemical screenings were normal.

She was treated with tricyclic antidepressants (clomipramine $150 \mathrm{mg}$ daily) and neuroleptics were

Behavioural Neurology . Vol 8 . 1995 
added later (trifluoperazine up to a maximum of $10 \mathrm{mg}$ daily). She also received a course of six electroconvulsive therapy (ECT) treatments.

Her condition improved slightly until, in July 1991, she started complaining of forgetfulness. There were also instances of very bizarre behaviour, e.g. bringing a baby's push chair with her to the day hospital. A psychometric assessment at this time revealed a NART score of 119 and a relative impairment in her WAIS performance score (WAIS verbal score 113, WAIS performance score 95). Chest X-rays, ECG and EEG were normal. The CT brain scan showed bilateral periventricular hypodensity and mild to moderate ventricular enlargement.

Hard neurological signs appeared towards the end of 1992, with generalized hyperreflexia, stooped and dyspraxic gait and a left extensor plantar response. The patient became very apathetic and withdrawn. Psychometric tests were repeated and revealed a further deterioration (WAIS verbal score 113, WAIS performance score 88 ).

The final diagnosis was of BD. Management was reviewed and the family advised accordingly.

\section{Case 2}

Mrs KR was a 55 year old right-handed hypertensive woman with a positive family history of dementia in her sister, who is 6 years her elder. At the age of 50 and following her father's death, she was seen by a psychiatrist for bereavement counselling.

During 1990 she became progressively more disorganized and unable to cope with her work as a personnel supervisor. She exhibited episodes of bizarre behaviour. On one occasion she wandered 30 miles from home to visit a prison where she knew none of the inmates. In 1991 she developed grandiose delusions of psychic powers and reported auditory hallucinations, saying that her father and other spirits were conversing with her. Her mood was only mildly depressed.

In July 1991, she was admitted to hospital after attacking a colleague at work without provocation. Physical examination was unremarkable apart from hypertension $(145 / 100 \mathrm{mmHg})$. Chest X-rays, ECG and EEG were normal. She responded to small doses of neuroleptic medication (chlorpromazine $25 \mathrm{mg}$ t.d.s.), her grandiose ideas resolving and the hallucinations becoming less frequent. She was however readmitted only 4 months after discharge from hospital as she was now living in squalor, neglecting all the housework, refusing to eat and causing embarrassment to her relatives because of her social disinhibition. Neurological signs had appeared, with generalized hyperreflexia, increased tone in the upper limbs and reduced arm swing.
Psychometric assessment on admission gave a NART score of 105 , with a current WAIS verbal score of 90 and a performance score of 88 . Six months later her verbal score was 76 and her performance score 78 .

CT brain scan in August 1991 showed diffuse, bilateral periventricular white matter hypodensity, a small hypodense area in the left frontal lobe and ventricular enlargement more pronounced in the frontal horns.

The final diagnosis was that of $\mathrm{BD}$. The patient was discharged into a nursing home. When reviewed 4 months later she had also developed urinary incontinence.

\section{DISCUSSION}

Both cases fulfilled the criteria for the clinical diagnosis of $\mathrm{BD}$, with evidence of dementia confirmed by neuropsychological tests, the presence of one risk factor for cerebrovascular disease (hypertension), subcortical features of parkinsonism, rigidity and gait disturbance. One focal pyramidal sign was present in Case 1 (ST). In both cases there was radiological evidence of bilateral periventricular leukoaraiosis (Bennett et al., 1990; Roman et al., 1993). The onset of cognitive impairment prompted the radiological investigations which confirmed the presence of diffuse white matter disease. Before this, the symptomatology was strongly suggestive of a functional psychiatric disorder.

The association between schizophrenia and affective disorders with cerebrovascular disease has been well researched. Rabins et al. (1991) described a small sample of patients with schizophreniform symptoms after a stroke and found that right hemisphere lesions predominated and that the psychotic patients had greater ventricle to brain ratio (VBR), particularly in relation to frontal horns and third ventricle. Cerebral blood flow studies of individuals with schizophrenia have indicated both frontal hypoperfusion and relative hyperperfusion in the left medial temporal lobe depending on symptom profile (Friston et al., 1992; Liddle et al., 1992).

Studies have shown greater third and lateral VBR in patients with depression following stroke (Starkstein, 1988) and the left frontal lobe in particular appears to be implicated (Astrom et al., 1993). Depressed patients have been found to have increased VBRs (Dolan et al., 1985; Bird et al., 1986). Neuroimaging techniques have demonstrated reduction in cerebral blood flow and hypometabolism in the frontal lobes in depressed individuals (Baxter et al., 1985; Buchsbaum et al., 1986). 
The association between leukoaraiosis and depression was reported by Coffey et al. (1987) in a prospective study of depressed non-demented patients who had been successfully treated with ECT. Periventricular white matter disease was discovered in all subjects on MRI. However, in $80 \%$ of cases the onset of depression was after the age of 60 years. With advancing years, the expectation of finding white matter disease increases. The study of younger psychiatric hypertensive patients with radiological evidence of leukoaraiosis would help clarify the pathoplastic influence of white matter disease on the pathogenesis and progression of some forms of psychiatric illness.

Hypertension in association with white matter disease is not always linked with the development of cognitive impairment, especially when there is a satisfactory degree of cerebral perfusion (Shimada et al., 1990). It may, however, have a bearing on non-cognitive psychopathology and resistance to the successful treatment of functional psychiatric illness. The mechanism of this neuropathological-phenomenological interaction is still unclear and is likely to be complex. Mood disturbance and psychotic phenomena are frequently found in patients suffering from primary cortical degenerative conditions and are widely reported in the scientific literature (Burns et al., 1990).

These two cases are a reminder that significant functional psychopathology may precede ominous neuropsychiatric developments by several months or years in patients suffering from BD. The suspicion of the impending risk of a vascular dementia could have possibly led to the prescription of warfarin, asprin or other anticoagulant agents as well as hypotensive drugs. The antidepressant and neuroleptic treatment received by both patients does not call for criticism, as functional syndromes in demented patients can be pharmacologically treated, albeit in the short term (Joyce and Levy, 1989).

We suggest that BD should be considered in all hypertensive patients in their fifties with an apparent functional psychiatric illness of recent onset, especially if it proves resistant to treatment. Cognitive impairment may be initially very subtle, but should be vigorously sought. The assessment of this group of patients should include neuroimaging by CT or, preferably, MRI brain scan. Optimal management must also include careful control and treatment of blood pressure and cerebrovascular disease.

\section{REFERENCES}

Astrom M, Adolfsson R and Asplund K (1993) Major depression in stroke patients; a three year longitudinal study. Stroke, 24, 976-982.
Babikian V and Ropper AH (1987) Binswanger's Disease: a review. Stroke, 18, 2-12.

Baxter LR, Phelps ME, Mazziotta JC et al. (1985) Cerebral metabolic rates for glucose in mood disorders. Archives of General Psychiatry, 42, 441-447.

Bennett DA, Wilson RS, Gilley DW et al. (1990) Clinical diagnosis of Binswanger's Disease. Journal of Neurology, Neurosurgery and Psychiatry, 53, 961-965.

Bird JM, Levy R and Jacoby RJ (1986) Computed tomography with the elderly: changes over time in a normal population. British Journal of Psychiatry. 148, 8085.

Buchsbaum MS, Wu J, DeLisi LE et al. (1986) Frontal cortex and basal ganglia metabolic rates assessed by PET with 18-(F)2-deoxy glucose in affective illness. Journal of Affective Disorders, 10, 137-152.

Burns A, Jacoby R and Levy R (1990a) Psychiatric phenomena in Alzheimer's Disease. II: Disorders of perception. British Journal of Psychiatry, 157, 76-81.

Burns A, Jacoby R and Levy R (1990b) Psychiatric phenomena in Alzheimer's Disease. III: Disorders of mood. British Journal of Psychiatry, 157, 81-86.

Coffey CE, Hinkle PE and Weiner RD (1987) Electroconvulsive therapy of depression in patients with white matter hyperintensities. Biological Psychiatry, 22, 629-636.

Dolan RJ, Calloway SP and Mann AH (1985) Cerebral ventricular size in depressed subjects. Psychological Medicine, 15, 873-887.

Friston KJ, Liddle PF, Frith CD, Hirsch SR and Frackowiack RSJ (1992) The left medial temporal region and schizophrenia. Brain, 115, 367-382.

Goto K, Ishii N and Fukasaya H (1981) Diffuse white matter disease in the geriatric population. Radiology, 44, 194-204.

Hachinski VC, Potter P and Merskey H (1987) Leukoaraiosis. Archives of Neurology, 44, 21-23.

Joyce RM and Levy R (1989) Treatment of mood disorder associated with Binswanger's Disease. British Journal of Psychiatry, 154, 259-261.

Liddle PF, Friston KJ, Frith CD, Hirsch SR, Jones T and Frackowiack RSJ (1992) Patterns of cerebral blood flow in schizophrenia. British Journal of Psychiatry, 160, 179186.

O'Brien MD (1988) Vascular dementia is under-diagnosed. Archives of Neurology, 45, 797-798.

Peterson B and Summergrad P (1989) Binswanger's Disease Part II: Pathogenesis of sub-cortical arteriosclerotic encephalopathy and its relation to other dementing processes. Journal of Geriatric Psychiatry and Neurology, 2(4), 171-181.

Rabins PV, Starkstein SE, Robinson RG, (1991), Risk factors for developing Atypical (Schizophreniform) Psychosis following stroke, Journal of Neuropsychiatry and Clinical Neuroscience, 3; 6-9.

Roman GC, Tatemichi TK, Erkinjuntti T et al. (1993) Vascular dementia: diagnostic criteria for research studies. Neurology, 43, 250-260.

Shimada K, Kavamoto A, Matsubayashi K and Ozawa T (1990) Silent cerebrovascular disease in the elderly. Hypertension, 16, 692-699.

Starkstein SE, Robinson RG, Price TR, (1988), Comparison of Patients with and without Post-Stroke Major Depression matched for Size and Location of Lesion, Archives of General Psychiatry, 45; 247-252. 
Summergrad P and Peterson B (1989) Binswanger's Disease Part I: The clinical recognition of sub-cortical arteriosclerotic encephalopathy in elderly neuropsychiatric patients. Journal of Geriatric Psychiatry and Neurology, 2(3), 123133.

Van Swieten JC, Geyskes GG, Derix MM, Peeck BM, Ramos LM, van Latum JC and van Gijn J (1991)
Hypertension in the elderly is associated with white matter lesions and cognitive decline. Annals of Neurology, 30(6), 825-830.

Yao H, Sadoshima S, Ibayashi S, Kuwabara Y, Ichiya $Y$ and Fujishima W (1992) Leukoaraiosis and dementia in hypertensive patients. Stroke, 23(11), 16731677. 


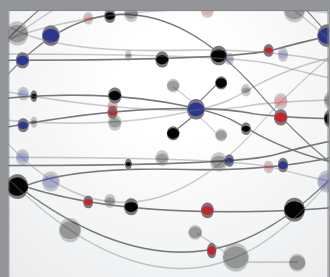

The Scientific World Journal
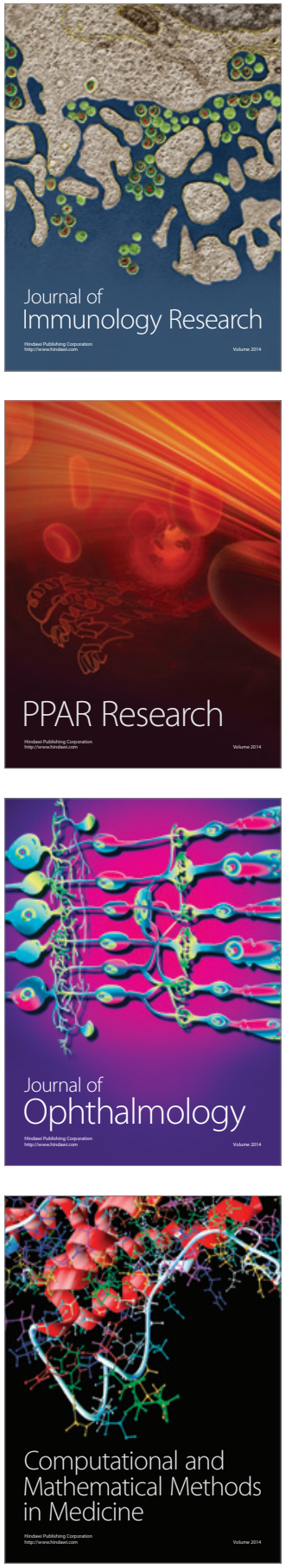

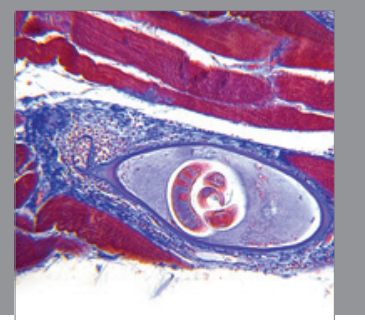

Gastroenterology

Research and Practice
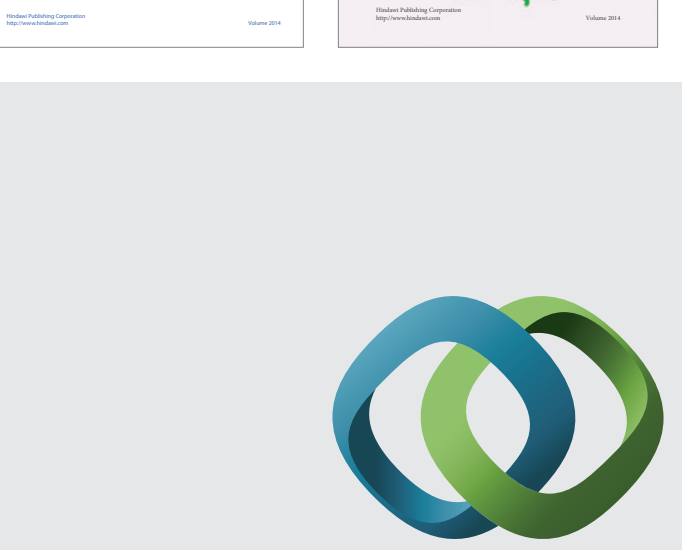

\section{Hindawi}

Submit your manuscripts at

http://www.hindawi.com
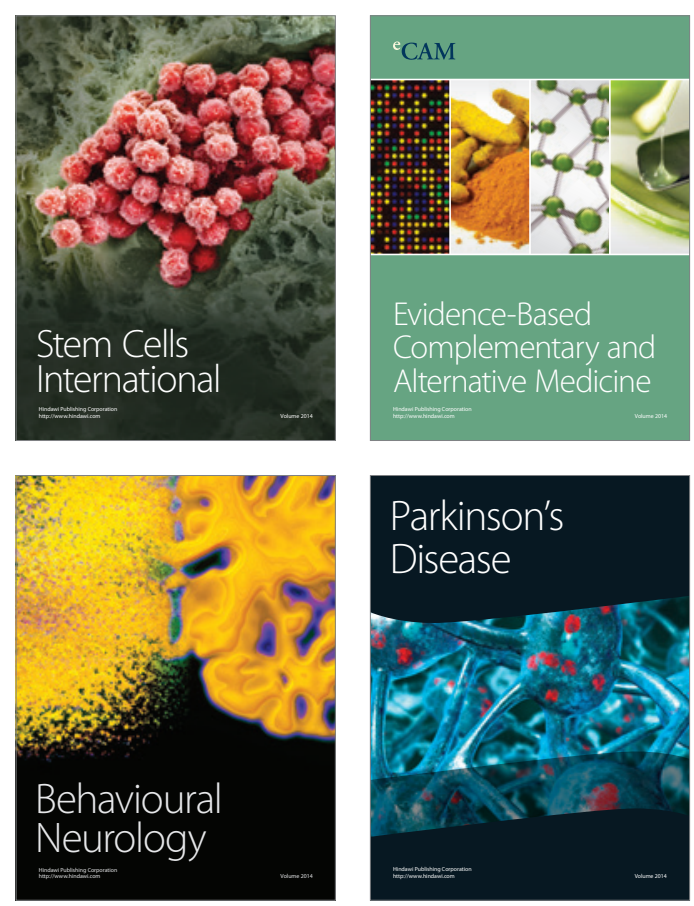

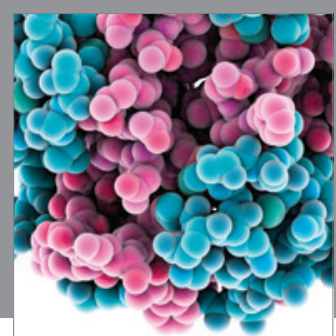

Journal of
Diabetes Research

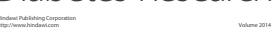

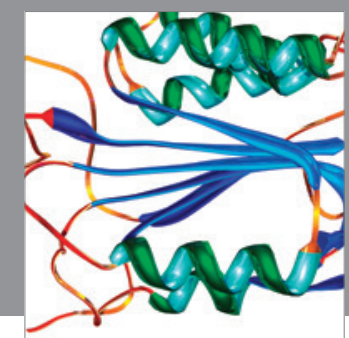

Disease Markers
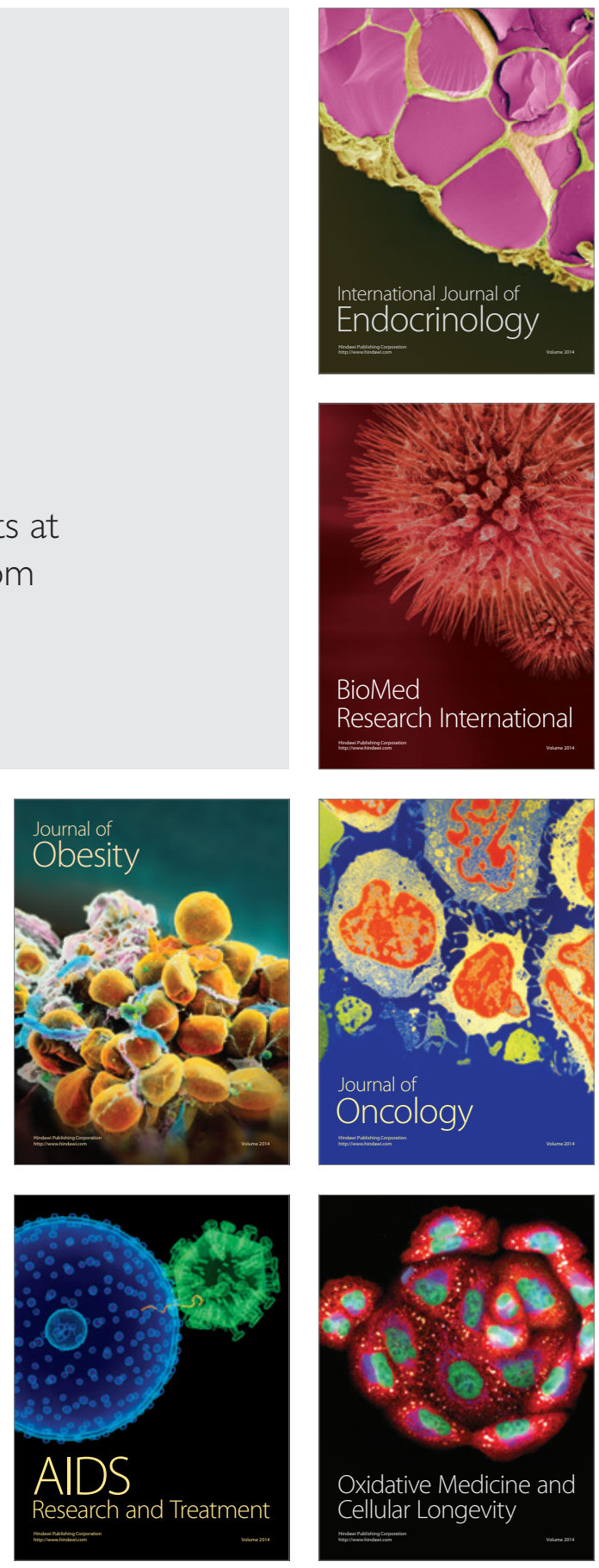